\title{
Effects of Imipramine, Nomifensine and d-Amphetamine on Type B Monoamine Oxidase, Cyclic AMP Phosphodiesterase and Dopamine- $\beta$-Hydroxylase
}

\author{
Hiroshi Izumi, Osamu Togashi,* Makoto Hayakari, \\ Shoryo Hayashi and Hikaru Ozawa \\ Pharmaceutical Institute, Tohoku University, Aobayama, Sendai and \\ Department of Biological Science, ${ }^{*}$ Pharmaceutical Laboratory, \\ Hoechst Japan Limited, Kawagoe
}

\begin{abstract}
Izumi, H., Togashi, O., Hayakari, M., Hayashi, S. and Ozawa, H. Effects of Imipramine, Nomifensine and d-Amphetamine on Type B Monoamine Oxidase, Cyclic AMP Phosphodiesterase and Dopamine- $\beta$-hydroxylase. Tohoku J. exp. Med., 1976, 118 (3), 223-231 — The three dissimilar structural antidepressant drugs, imipramine, nomifensine and d-amphetamine, were compared for their effects on type B monoamine oxidase, cyclic AMP phosphodiesterase and dopamine- $\beta$-hydroxylase. Three antidepressant drugs caused a dose-dependent inhibition on type $B$ monoamine oxidase. Of the three drugs, imipramine had a most potent effect. Unlike d-amphetamine, both imipramine and nomifensine inhibited the cyclic AMP phosphodiesterase activity at concentrations more than $10^{-4} \mathrm{M}$. No effect was observed below this concentration. All drugs seemed to have little or no effects on the partially purified dopamine- $\beta$-hydroxylase activity. The weak inhibitory effects of nomifensine on these three enzymes may not be attributable to its antidepressant properties. Morphine had no effect on the three enzyme activities. —— antidepressant drugs; type B monoamine oxidase; cyclic AMP phosphodiesterase; dopamine- $\beta$-hydroxylase
\end{abstract}

The mechanism of action of the antidepressant drugs remains obscure despite of a multitude of experimental studies documenting a variety of pharmacological and biochemical effects (Davis and Brody 1966; Garattini and Dukes 1966; Carlsson et al. 1969a, b; Chowdhury et al. 1969; Frisk-Homberg and van der Kleijin 1972; Caratsch and Waser 1973; Kannengiesser et al. 1973).

It has been suggested by many investigators that the primary action of the antidepressant drugs is to block neuronal and synaptosomal binding of catechol and indole amines in the brain, thus increasing monoamine contents of the tissue (Glowinski and Axelrod 1964; Anden et al. 1969). However, it has also been shown in several laboratories that tricyclic antidepressant drug, imipramine, influences some enzyme activities in vitro (Goldstein and Contrera 1961; Ramsden 1970; Roth and Gillis 1974a, b). In monoamine oxidase, the type B monoamine oxidase was further shown to be more susceptible to inhibition by this drug than was the type A monoamine oxidase (Roth and Gillis 1974b).

Received for publication, October 30, 1975. 
In the present study we have compared the effects of imipramine, nomifensine and $d$-amphetamine on the activities of type $B$ monoamine oxidase, cyclic AMP phosphodiesterase and partially purified dopamine- $\beta$-hydroxylase. We have also investigated the effect of morphine on the above three enzyme activities since this drug acts at the central nervous system like the antidepressant drugs.

\section{Materials and Methods}

ATP, 5'-AMP, tris(hydroxymethyl)aminoethane and catalase were purchased from Sigma Chemical Co. Tyramine hydrochloride, cyclic AMP and ${ }^{14} \mathrm{C}-\beta$-phenethylamine were obtained from Daiichi Pure Chemical Co. $\left[8^{\left.-{ }^{14} \mathrm{C}\right]}\right.$ cyclic AMP was obtained from Schwarz Bio-Research. Imipramine was generously supplied by Ciba-Geigy (Japan) Ltd. All other chemcials were reagent grade preparations obtained from various commercial sources.

Assay of monoamine oxidase

Type B monoamine oxidase activities were measured by a modification of the procedure described by Roth and Gillis $(1974 \mathrm{~b})$. The reaction mixtures containing $10 \mu \mathrm{M}$ ${ }^{14} \mathrm{C}$ - $\beta$-phenethylamine and varying amounts of the drugs in a total volume of $1 \mathrm{ml}$ of 0.05 $\mathrm{M}$ potassium phosphate buffer, $\mathrm{pH}$ 7.25, were incubated with rat brain mitochondrial monoamine oxidase at $37^{\circ} \mathrm{C}$ for $15 \mathrm{~min}$. Reactions were terminated by the addition of $0.1 \mathrm{ml}$ of $0.25 \mathrm{M}$ zinc sulfate followed by addition of $0.1 \mathrm{ml}$ of a saturated solution of barium hydroxide. The resulting precipitate was removed by centrifugation and $0.5 \mathrm{ml}$ aliquots of the supernatant solution were passed through Dowex 50W-X4 column (approximately $1 \times 1.5 \mathrm{~cm}$, sodium form, $\mathrm{pH} 6.0$ ). The products, phenylacetic acid and/or aldehyde, formed in the reactions were eluted from the columns with $\mathrm{H}_{2} \mathrm{O}$. A total effluent volume of $3 \mathrm{ml}$ was collected, and a $1.0 \mathrm{ml}$ aliquot was removed, added to $10 \mathrm{ml}$ of Bray's solution (Bray 1960) and radioactivity was determined in a scintillation spectrometer (Packard Tri-Carb Model 3380) and corrected for quenching using an external standardization system.

\section{Assay of cyclic AMP phosphodiesterase}

Enzyme activities were examined by the method of Pöch (1971) with a cyclic AMP concentration of $3.6 \times 10^{-4} \mathrm{M}$ as described previously (Izumi et al. 1975). Enzyme activities were measured as the rate of hydrolysis of cyclic AMP in a standard medium (final volume $0.5 \mathrm{ml}$ ) containing ${ }^{14} \mathrm{C}$-cyclic AMP $(0.05 \mu \mathrm{Ci}), 3.0 \mathrm{mg}$ Mg-acetate, 2.0 $\mathrm{mM} 5^{\prime}$-AMP, $100 \mathrm{mM}$ Tris-HCl buffer ( $\mathrm{pH}$ 7.4) and the enzyme preparations. Incubations were run at $37^{\circ} \mathrm{C}$ for $15 \mathrm{~min}$ and the reactions were stopped by adding $0.2 \mathrm{ml}$ of zino sulfate and $0.2 \mathrm{ml}$ of $0.15 \mathrm{M}$ barium hydroxide. After centrifugation $(1,000 \times \mathrm{g}$ for $10 \mathrm{~min}), 0.3 \mathrm{ml}$ of the supernatant solution was transferred into a counting vial with $10 \mathrm{ml}$ of scintillation medium ( $4 \mathrm{~g}$ of PPO, $100 \mathrm{mg}$ of demethyl POPOP, $1,000 \mathrm{ml}$ of toluene, $400 \mathrm{ml}$ of 99.5 per cent ethanol and $100 \mathrm{ml}$ of dioxane). The radioactivity was then determined by a liquid scintillation spectrometer.

Assay of dopamine-p-hydroxylase

Enzyme activities were assayed by the following conversion of tyramine to octopamine according to the procedure of Van der Schoot et al. (1963) as previously described (Oyama et al. 1975). One $\mathrm{ml}$ of the mixture contained potassium phosphate buffer ( $\mathrm{pH} \mathrm{5.5)} 100$ $\mu$ moles, ascorbic acid $10 \mu$ moles, fumaric acid $10 \mu$ moles, tyramine hydrochloride $10 \mu$ moles, catalase 200 Sigma Units and the partially purified enzyme preparations. The reaction mixtures were preincubated for $5 \mathrm{~min}$ at $37^{\circ} \mathrm{C}$ without substrate. The reactions were started by adding the substrate and were incubated for $15 \mathrm{~min}$ at $37^{\circ} \mathrm{C}$. The reactions were terminated by adding $2 \mathrm{ml}$ of $4 \mathrm{~N}$ ammonium hydroxide. The complete reaction mixture was used as the control, but the reactions were terminated without the final 
incubation. The amounts of octopamine formed were determined after conversion of octopamine to $\rho$-hydroxybenzaldehyde. This was done by measuring the absorbance at $330 \mathrm{~m} \mu$.

Preparation of rat brain mitochondrial and $105,000 \times g$ supernatant fraction

Sprague-Dawley male rats (CLEA, Japan, Inc.), weighing 250-300 g, were used in the experiments. After animals were decapitated, the brains were isolated and chilled in an icecold solution containing $0.12 \mathrm{M}$ sucrose and $3.0 \mathrm{mM} \mathrm{MgSO}_{4}$. Subsequently, the cerebral cortex was isolated by the methods of Glowinski and Iversen (1966) and was homogenized in 9 volumes of the same isotonic cold solution using a glass homogenizer with a loose Teflon pestle. The homogenates were centrifuged at $4^{\circ} \mathrm{C}$ for $20 \mathrm{~min}$ at $1,000 \times \mathrm{g}$. The resulting supernatant fluid was centrifuged at $10,000 \times \mathrm{g}$ for $20 \mathrm{~min}$. The precipitate was diluted in the same sucrose medium and used as enzyme source for monoamine oxidase. The supernatant fluid was centrifuged at $105,000 \times \mathrm{g}$ for $60 \mathrm{~min}$ at $4^{\circ} \mathrm{C}$. The resulting supernatant was noted as the $105,000 \times \mathrm{g}$ supernatant and used as enzyme source for cyclic AMP phosphodiesterase.

\section{Preparation of dopamine- $\beta$-hydroxylase}

Dopamine- $\beta$-hydroxylase was prepared from bovine adrenal medulla according to the method of Foldes et al. (1972). The pure chromaffin granules were isolated from fresh bovine adrenal medulla by the sucrose density gradient and subsequent solubilization using Triton-X100 and purification by DEAE-cellulose column chromatography were performed. In this work, the enzyme obtained at the step of DEAE-cellulose chromatography was used.

\section{Protein determination}

The protein contents were determined by the procedure described by Lowry et al. (1951) with crystalline bovine serum albumin as the standard.

\section{Results}

Fig. 1 shows the effects of varying protein concentrations upon the rate of accumulation of ${ }^{14} \mathrm{C}$-labeled phenylacetic acid and/or aldehyde formed from ${ }^{14} \mathrm{C}$ labeled phenethylamine $(10 \mu \mathrm{M})$ in rat brain mitochondrial fraction; the rate of

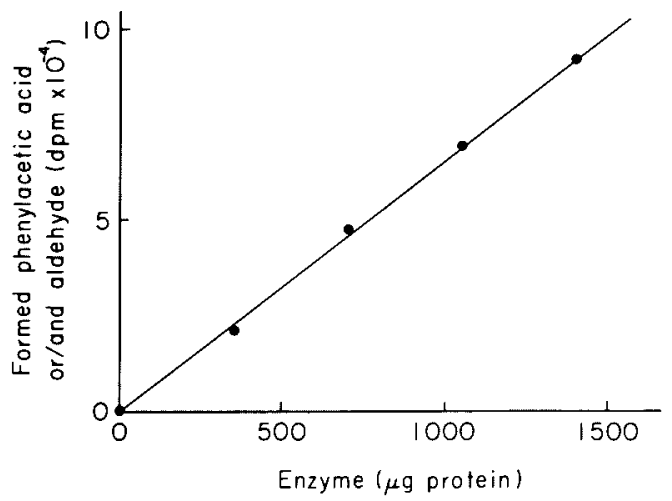

Fig. 1. Monoamine oxidase activity of rat brain mitochondrial fraction as a function of enzyme concentration. Each value represents the mean of 3 experiments. Incubations were conducted for $15 \mathrm{~min}$ at $37^{\circ} \mathrm{C}$. 
phenethylamine deamination was proportional to protein concentration. The deamination appeared to be linear against the time of incubation up to $20 \mathrm{~min}$. On this basis, in most experiments the reactions were carried out for 15 min employing about $1.0 \mathrm{mg}$ protein per $1.0 \mathrm{ml}$ of incubation medium.

As can be seen in Fig. 2, the type $B$ monoamine oxidase activity of the mitochondrial fraction was inhibited by the three antidepressant drugs depending on their concentrations. Imipramine was the most potent inhibitor. At $10^{-4} \mathrm{M}$, imipramine inhibited deamination of phenethylamine by about $50 \%$, and at $10^{-3} \mathrm{M}$, more than $85 \%$. Besides imipramine, $\mathrm{d}$-amphetamine and nomifensine also inhibited the enzyme activity; at a concentration of $10^{-3} \mathrm{M} \mathrm{d}$-amphetamine and nomifensine reduced the activity by $45,35 \%$, respectively. Morphine did not produce any significant effect.

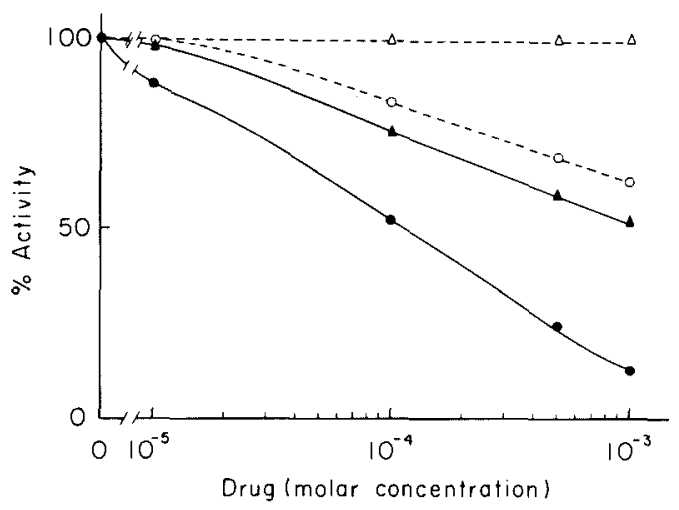

Fig. 2. Effects of imipramine, nomifensine, d-amphetamine and morphine on brain mitochondrial monoamine oxidase. Each value represents the mean of 3 experiments. The incubation was performed as described in the methods. Deaminated product formed was assayed as described in the text.

$\bullet-\bullet$, imipramine; $0 \cdots-$, nomifensine; $\Delta-\Delta, d$-amphetamine; $\Delta--\Delta$, morphine.

Fig. 3 shows a comparison of the effects of the above three antidepressant drugs and morphine on cyclic AMP phosphodiesterase in rat brain. The enzyme activity was significantly inhibited by imipramine and nomifensine of more than $10^{-4} \mathrm{M}$. Both imiprmaine and nomifensine at a concentration of $10^{-4} \mathrm{M}$ resulted in only $10 \%$ inhibition of control activity. At $10^{-3} \mathrm{M}$, imipramine and nomifensine reduced the enzyme activity by 75 and $38 \%$, respectively. Below $10^{-4} \mathrm{M}$, no effect on enzyme activity was observed. d-Amphetamine and morphine seemed to have no inhibitory effect.

Fig. 4 shows the effects of the three antidepressant drugs and morphine on the partially purified dompanine- $\beta$-hydroxylase activity. At $10^{-4} \mathrm{M}$, imipramine reduced the enzyme activity by about $15 \%$ as compared with the control value. At higher concentrations of imiprmaine, precipitates were formed in the test tube during the incubation, so that we could not assay the enzyme activity. Nomifensine, 


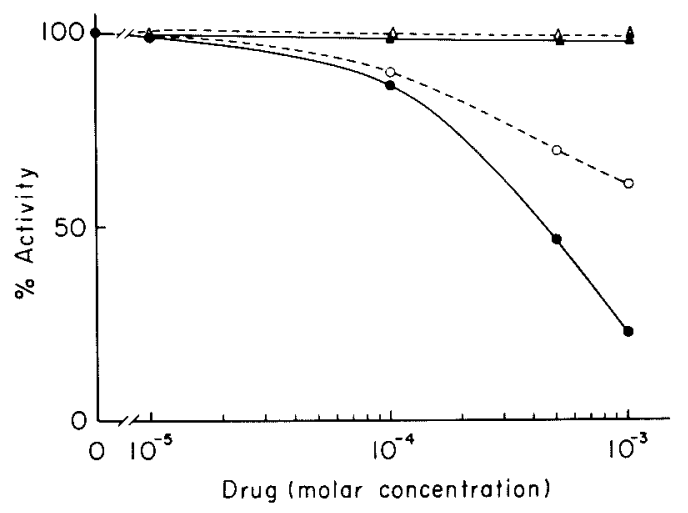

Fig. 3. Effects of imipramine, nomifensine, $d$-amphetamine and morphine on brain cyclic AMP phosphodiesterase. Each value represents the mean of 3 experiments. The incubation was performed as described in the methods.

$\bullet-\bullet$, imipramine; $\bigcirc \cdots \circ$, nomifensine; $\Delta-\Delta, d$-amphetamine; $\Delta \cdots \Delta$, morphine.

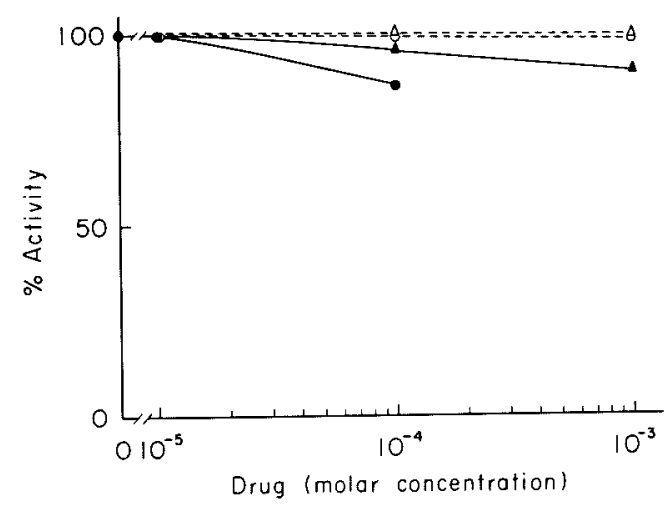

Fig. 4. Effects of imipramine, nomifensine, d-amphetamine and morphine on partially purified dopamine- $\beta$-hydroxylase. Each value represents the mean of 3 experiments. The incubation was performed as described in the methods.

$\bullet-\bullet$, imipramine; $0--\circ$, nomifensine; $\mathbf{\Delta - \Delta ,}$ d-amphetamine; $\Delta \cdots \Delta$, morphine.

d-amphetamine and morphine seemed to have no effect on the enzyme activity. Incubation at a substrate concentration of $1 \mathrm{mM}$ gave similar results.

\section{Discussion}

During the past few years, various attempts have been made to clarify the mode of action of antidepressant drugs (Davis and Brody 1966; Garattini and Dukes 1966; Carlsson et al. 1969a, b; Chowdhury et al. 1969; Frisk-Homberg and van der Kleijin 1972; Caratsch and Waser 1973; Kannengiesser et al. 1973; Patel et al. 1975). 
$\beta$-Phenethylamine has been detected in the brain and peripheral tissues of man (Levine et al. 1964; Inwang et al. 1973) and animals (Nakajima et al. 1964; Jackson and Temple 1970; Saavedra and Axelrod 1973). Some authors (Saavedra and Fischer 1970; Sabelli and Mosnaim 1974) suggested that $\beta$-phenethylamine might be a"modulator" in the central nervous system, and some others reported that type A monoamine oxidase catabolized the transmitter amines, serotonin and norepinephrine and that type B monoamine oxidase catabolized phenethylamine (Yang and Neff 1973). Therefore, we investigated the effects of the three antidepressant drugs with dissimilar structures, imipramine, nomifensine and $\mathrm{d}$ amphetamine on the activity of the type B monoamine oxidase. As shown in Fig. 2 , the phenethylamine deamination was strongly inhibited by imipramine. These results corresponded to the results obtained by Roth and Gillis (1974b) who found that $50 \%$ inhibition of type $B$ monoamine oxidase activity occurred at imipramine concentration of $3 \times 10^{-5} \mathrm{M}$. Both nomifensine and d-amphetamine weakly reduced the enzyme activity at relatively high concentrations. Glowinski et al. (1966) previously found that when $15 \mathrm{mg} / \mathrm{kg}$ body weight of d-amphetamine was injected to rat intraperiotoneally, the concentration of $d$-amphetamine in the body fluid was $5 \times 10^{-5} \mathrm{M}$. In the present study, however, d-amphetamine at this concentration seemed to have little effect on the type B monoamine oxidase activity. The results disagree with the previously reported finding on d-amphetamine inhibition of monoamine oxidase activity obtained by using ${ }^{3} \mathrm{H}$-norepinephrine as the substrate (Glowinski et al. 1966). On the other hand, it has been reported that the antidepressant drugs, d-amphetamine and imipramine, have different effects on the endogenous norepinephrine content of the brain: d-amphetamine, at high doses, can decrease the endogenous level of norepinephrine (Vogt 1954), while imipramine have no such effect (Salser et al. 1964). From these reports and the present studies, it is conceivable that $d$-amphetamine could inhibit the deamination of norepinephrine (type A monoamine oxidase) more strongly than the deamination of phenethylamine (type B monoamine oxidase).

Several recent studies demonstrated a lack of correlation between the ability of triclycic antidepressant drugs to prevent uptake and binding of biogenic amines in the brain and clinical efficacy of these drugs (Horn et al 1971; Lahti and Maickel 1971). Recently, Roth and Gillis (1974a) have suggested that tricyclic antidepressant drugs may act in man not only by preventing uptake of biogenic amines by brain neurons but may also prevent loss of these monoamines by inhibiting monoamine oxidase. However, considering the weak inhibition of type B monoamine oxidase by d-amphetamine and nomifensine, the inhibitory effects of both drugs may not be attributable to their antidepressant properties.

It has previously been postulated by Abdulla and Hamadah (1970) that depression and mania might be attributable to a decrease or increase in the level of cyclic AMP in the body. Based on this hypothesis, Ramsden (1970) investigated the effects of various antidepressant drugs on the enzymic hydrolysis of cyclic AMP, using the enzyme cyclic AMP phdsphodiesterase extracted from ox 
heart. All the antidepressant drugs they tried showed considerable inhibition of cyclic AMP phosphodiesterase. As seen in Fig. 3, imipramine and nomifensine exerted a dose dependent inhibition on rat brain cyclic AMP phosphodiesterase. However, the concentration required for significant inhibition was more than $10^{-4} \mathrm{M}$. These results also suggest that the inhibition of cyclic AMP phosphodiesterase by impiramine and nomifensine might not be responsible for their main antidepressant effects in brain.

It has been reported that dopamine- $\beta$-hydroxylase activity is inhibited by various sulfur containing compounds; diethyldithiocarbamate and disulfiram (Goldstein et al. 1965), thiourea derivatives (Johnson et al. 1969; Oyama et al. 1975), D-cysteine, coenzyme A (Nagatsu et al. 1967) and L-cysteine (Nagatsu et al. 1967; Izumi et al. 1976) and by some chelating agents (Green 1964). Previously, Goldstein and Contrera (1961) reported that imipramine, in relatively high doses, inhibited dompanine- $\beta$-hydroxylase, and that when the concentration of imipramine to substrate (dopamine) was $2: 1$, approximately $50 \%$ inhibition of norepinephrine synthesis was achieved. However, as shown in Fig. 4, nomifensine, d-amphetamine and morphine had no effect on the partially purified dopamine- $\beta$-hydroxylase. Imipramine at $10^{-4} \mathrm{M}$ concentration exerted a slight inhibition. However, this inhibition does not seem to be attributable to its antidepressant effect.

At present, although we cannot establish the mode of action of the antidepressant drugs from the present studies, the available evidence indicates that imipramine has the more potent inhibitory properties on type B monoamine oxidase, cyclic AMP phosphodiesterase and dopamine- $\beta$-hydroxylase than other two drugs. On the other hand, in view of the potent inhibitor of norepinephrine uptake by nomifensine in whole brain synapotosomes, and also of the fact that nomifansine is 130 times as potent as the tricyclic compounds such as imipramine (Schacht and Heptner 1974), it seems likely that nomifensine owes some of its antidepressant properties to this mechanism. It seems, therefore, to be difficult to explain the mode of action of various antidepressant drugs by one mechanism only. Further investigation is necessary to determine the definite mode of action of each antidepressant drug.

\section{References}

1) Abdulla, Y.H. \& Hamadah, K. (1970) $3^{\prime}, 5^{\prime}$-cyclic adenosine monophosphate in depression and mania. Lancet, 1, 378-381.

2) Anden, N.E., Carlsson, A. \& Haggendal, J. (1969) Adrenergic mechanism. A. Rev. Pharmacol., 9, 119-134.

3) Bray, G.A. (1960) A simple efficient liquid scintillator for counting aqueous solutions in a liquid scintillation counter. Analyt. Biochem., 1, 279-285.

4) Caratsch, G.G. \& Waser, P.G. (1973) Tricyclic antidepressants: action on synaptosomal acetylcholinesterase and ATPase in the brain of guinea pigs and subcellular distribution. Neuropharmacol., 12, 563-575

5) Carlsson, A., Corrodi, H., Fuxe, K. \& Hokfelt, T. (1969a) Effect of antidepressant drugs on the depletion of intraneuronal brain 5-hydroxytryptamine stores caused by 4-methyl- $\alpha$-ethyl-m-tyramine. Eur. J. Pharmacol., 5, 357-366.

6) Carlsson, A., Corrodi, H., Fuxe, K. \& Hokfelt, T. (1969b) Effects of some antidepressant drugs on the depletion of intraneuronal brain catechol amine stores 
caused by $4 a$-dimethyl-m-tyramine. Eur. J. Pharmacol., 5, 367-373.

7) Chowdhury, A.K., Rogers, H.H., Skinner, A., Spector, R.G. \& Watts, D.C. (1969) The influence of psychotropic drugs on aldolase, mitochondrial dehydrognease and $\mathrm{Mg}^{+}+\mathrm{Na}^{+} \mathrm{K}^{+}$adenosine triphosphatase. Br. J. Pharmacol., 37, 459-467.

8) Davis, D.W. \& Brody, T.M. (1966) Inhibition of $\mathrm{Na}^{+}, \mathrm{K}^{+}$-activated adenosine triphosphatase activity in rat brain by substituted phenothiazines. Biochem. Pharmacol., $15,703-710$.

9) Foldes, A., Jeffrey, L., Preston, B.N. \& Austin, L. (1972) Dopamine $\beta$-hydroxylase of bovine adrenal medullae. Biochem. J., 126, 1209-1217.

10) Frisk-Homberg, M. \& van der Kleijin, E. (1972) The relationship between the lipohilic nature of ticyclic neuroleptics and antidepressants, and histamine release. Eur. J. Pharmacol., 18, 139-147.

11) Garattini, S. \& Dukes, M.N.G. (1966) Antidepressant drugs, Excerpta Medica foundation, Amsterdam-New York-London-Milan-Tokyo-Buenos Aires.

12) Glowinski, J. \& Axelrod, J. (1964) Inhibition of uptake of tritiated-noradrenaline in the intact rat brain by imipramine and structurally related compounds. Nature, Lond., 204, 1318-1319.

13) Glowinski, J. \& Iversen, L.L. (1966) Catechol amines in rat brain. I. Disposition of norepinephrine- ${ }^{3} \mathrm{H}$, and dopa ${ }^{3} \mathrm{H}$ in various regions of the brain. $J$. Neurochem., $13,655-669$.

14) Glowinski, J., Axelrod, J. \& Iversen, L.L. (1966) Regional studies of catecholamines in the rat brain. IV. Effects of drugs on the disposition and metabolism of ${ }^{3} \mathbf{H}$ norepinephrine and ${ }^{3} \mathrm{H}$-dopamine. J. Pharmac. exp. Ther., 153, 30-4l.

15) Goldstein, M. \& Contrera, J.F. (1961) Inhibition of dopamine $\beta$-oxidase by imipramine. Biochem. Pharmacol., 7, 278-279.

16) Goldstein, M., Lauber, E. \& McKereghan, M.R. (1965) Studies of the purification and characterization of 3,4-dihydroxyphenylethyalmine $\beta$-hydroxylase. J. biol. Chem., 240, 2066-2072.

17) Green, A.L (1964) The inhibition of dopamine- $\beta$-oxidiase by chelating agents Biochin. biophys. Acta, 81, 394-397.

18) Horn, A.S. Coyle, J.T. \& Synder, S.H. (1971) Catecholamine uptake by synaptosomes from rat brain. Structure-activity relationships of drugs with differential effects on dopamine and norepinephrine neurons. Molec. Pharmacol., 7, 66-80.

19) Inwang, E., Mosnian, A. \& Sabelli, H. (I973) Isolation and characterization of phenylethylamine and phenylethanolamine from human brain. J. Neurochem., 20, 1469-1473.

20) Izumi, H., Oyama, H. \& Ozawa, H. (1975) The stimulatory effect of the boiled supernatant on cyclic AMP formation in synaptosomes from rat cerebral cortex. Japan. J. Pharmacol., $25(4), 375-381$.

21) Izumi, H. Oyama, H., Hayakari, M. \& Ozawa, H. (1976) Irreversible inhibition of dopamine- $\beta$-hydroxylase by cysteine. Biochem. Pharmacol., 25, 488-489.

22) Jackson, D.M. \& Temple, D.M. (1970) $\beta$-phenylethylamine as a cardiotonic constituent of tissue extracts. Comp. gen. Pharmacol., 1, 155-159.

23) Johnson, G.A., Boukma, S.J. \& Kim, E.G. (1969) Inhibition of dopamine- $\beta$-hydroxylase by aromatic and alkyl thioureas. J. Pharmac. exp. Ther., 168, 229-234.

24) Kannengiesser, M.H., Hunt, P. \& Raynaud, J.P. (1973) An in vitro model for the study of psychotropic drugs and as a criterion of antidepressant activity. Biochem. Pharmacol., 22, 73-84.

25) Lahti, W.E. \& Maickel, R.P. (1971) The tricyclic antidepressants-inhibition of norepinephrine uptake as related to potentiation of norepinephrine and clinical efficacy. Biochem. Pharmacol., 20, 482-486.

26) Levine, R.J., Nirenberg, P.Z., Udenfriend, S. \& Sjoerdsma, A. (1964) Urinary excretion of phenethylamine and tyramine in normal subjects and heterozygous carriers of phenylketonuria. Life Sci., 3, 65l-656.

27) Lowry, O.H., Rosebrough, N.J., Farr, A.C. \& Randall, R.J. (1951) Protein measurement with the folin phenol reagent. J. bicl. Chem., 193, 265-275. 
28) Nagatsu, T., Kuzuya, H. \& Hidaka, H. (1967) Inhibition of dopamine $\beta$-hydroxylase by sulfhydryl compounds and then the nature of the natural inhibitors. Biochim. biophys. Acta, 139, 319-327.

29) Nakajima, T., Kakimoto, Y. \& Sano, I. (1964) Formation of $\beta$-phenylethylamine in mammalian tissue and its effect on motor activity in the mouse. J. Pharmac. exp. Ther., 143, 319-325.

30) Oyama, H., Izumi, H. \& Ozawa, H. (1976) Inhibition of dopamine $\beta$-hydroxylase by some new thiourea derivatives. Biochem. Pharmacol., 25, 277-280.

31) Patel, G.J., Schatz, R.P., Constantinides, S.M. \& Lah, H. (1975) Effect of desipramine and pargyline on brain gamma-amino butyric acid. Biochem. Pharmacol., 24, 57-60.

32) Pöch, G. (1971) Assay of phosphodiesterase with radioactivity labeled cyclic 3', 5'AMP as substrate. Naunyn-Schmiedebergs Arch. Pharmak., 268, 272-299.

33) Ramsden, E.N. (1970) Cyclic A.M.P. in depression and mania. Lancet, 2, 108

34) Roth, J.A. \& Gillis, C.N. (1974a) Inhibition of lung, liver and brain monoamine oxidase by imipramine and desipramine. Biochem. Pharmacol., 23, 1138-1140.

35) Roth, J.A. \& Gillis, C.N. (1974b) Deamination of $\beta$-phenylethylamine by monoamine oxidase - inhibition by imipramine. Biochem. Pharmacol., 23, 2537-2545.

36) Saavedra, J.M. * Axelrod, J. (1973) International Congress on 5-HT and Indolealkylamines in Brain, Cagliari, Sardinia, June.

37) Saavedra, J.M. \& Fischer, E. (1970) Autagonism of $\beta$-phenylethylamine derivatives and serotonin blocking drugs upon seretonin, tryptamine and serotonin, reserpine behavioral depression in mice. Arzneimittel-Forsch., 20, 952-957.

38) Sabelli, H.C. \& Mosnain, A.D. (1974) Phenyethylamine hypothesis of affective behavior. Ame. J. Phychiat., 131, 695-699.

39) Salser, F., Bickel, M.H. \& Brodie, B.B. (1964) The actions of desmethylimipramine in counteracting sedation and cholinergic effects of reserpinelike drugs. J. Pharmac exp. Ther., 144, 321-329.

40) Schacht, V. \& Heptner, W. (1974) Effect of nomifensine (Hoe 984), a new antidepressant, on uptake of noradrenaline and serotonin and on release of noradrenaline in rat brain synaptosomes. Biochem. Pharmacol., 27, 3413-3422.

41) Van der schoot, J.B., Creveling, C.R., Nagatsu, T. \& Udenfriend, S. (1963) On the mechanism of inhibitors of dopamine- $\beta$-oxidase by benzyloxyamines. $J$. Pharmac. exp. Ther., 141, 74-78.

42) Vogt, M. (1954) The concentration of sympathin in different parts of the central nervous system under normal conditions and after the administration of drugs. $J$. Physiol., Lond., 123, 451-481.

43) Yang, H-Y. \& Neff, N.H. (1973) $\beta$-phenylethylamine: a specific substrate for type B monoamine oxidase of brain. J. Pharmac. exp. Ther., 187, 365-371. 